\title{
INTRODUCCIÓN AL DOSSIER \\ LA GUERRA CIVIL ESPAÑOLA: NUEVAS MIRADAS, PERSPECTIVAS Y LÍNEAS DE INVESTIGACIÓN
}

\author{
Carmen González Martínez (UMU) \\ Universidad de Murcia \\ cargonza@um.es
}

\author{
Sandra Souto Kustrín (CSIC) \\ Consejo Superior de Investigaciones Científicas \\ sandra.souto@cchs.csic.es
}

\begin{abstract}
A Julio Aróstegui, in Memoriam
Porque su obra nos ayuda a reflexionar sobre la República y la Guerra con apasionamiento, pero también con libertad.
\end{abstract}

\section{La Segunda República Española en la historia de España y de Europa}

El 18 de julio de 1936 el fracaso de un golpe militar contra el gobierno legítimo de la Segunda República española dio comienzo a una cruenta guerra civil que duró casi tres años, y cuyo resultado llevó a casi cuarenta años de dictadura. Sin embargo, el golpe militar se había ido gestando mucho antes. Como dijo en el 70 aniversario de la guerra civil el profesor Julio Aróstegui, para "explorar las causas profundas de la sublevación militar contra el gobierno de la República (...) es preciso adentrarse en la investigación no en uno, sino en varios y superpuestos plazos y perspectivas temporales".

La guerra fue el resultado directo de un golpe de Estado iniciado en Melilla, una de las principales ciudades del protectorado español en Marruecos, el 17 de julio de 1936, y de su fracaso; y fue impulsado por las resistencias a las reformas introducidas en el primer bienio republicano (19311933), y el enconamiento de las derechas españolas tras las elecciones de febrero de 1936 que dieron el triunfo a la coalición de izquierdas organizada en el Frente Popular.

Pero el conflicto bélico hunde sus raíces en la crisis general que se había abierto en España a partir de la crisis de 1917, que implicaba un debate y una contraposición de fuerzas sobre cómo -y con qué características- debía de producirse la modernización económica y social en España y bajo qué régimen político: la República del 14 abril de 1931, un intento de democratización homologable a otros realizados en la Europa de entreguerras, "no creó ninguno de los problemas que hubo de intentar resolver". Dicha crisis mostró las dificultades de transformación, común a las sociedades mediterráneas y de Europa Oriental, desde unas sociedades agrarias tradicionales a unas capitalistas

${ }^{1}$ Aróstegui, Julio, Por qué el 18 de julio... y después, Barcelona, Flor del Viento, 2006, pág. 105. 
modernas, y la dificultad de establecer regímenes que garantizaran la estabilidad social y de articular un Estado capaz de ser motor y regulador de las transformaciones socioeconómicas. Se vincula también claramente a la crisis que vivió Europa en el periodo comprendido entre las dos guerras mundiales, por el impacto de la Primera Guerra Mundial que aceleró el desarrollo económico, agudizando las tensiones sociales, la aparición de varios proyectos de revolución del proletariado no existentes anteriormente y el crecimiento de fórmulas autoritarias y fascistas. La movilización de masas tras la Gran Guerra, incluso donde no hubo revoluciones, generó grandes conflictos que, en último término, eran "sobre el poder y sobre cómo sería distribuido dentro de las diferentes sociedades europeas, con qué clase de sistemas políticos y con qué valores centrales".2

La Segunda República fue un nuevo proyecto de resolución de la crisis -tras el fracasado intento de la dictadura del general Miguel Primo de Rivera-, que tampoco la resolvió, sino que la agudizó, convirtiéndose en el momento álgido de la misma. Así, si entre la Primera Guerra Mundial y 1929, aproximadamente, se produjo la separación nítida entre reformismo, revolución y dictadura (autoritaria o fascista), la pugna que se produjo desde 1918 en Europa entre socialismo bolchevique, fascismo y democracia radical tuvo "en el escenario español (...) su desarrollo principal en el tiempo de la República": en la década de los treinta, España fue "un microcosmos" donde "los afanes democrático-liberales, las ilusiones revolucionarias, las pretensiones del fascismo y las resistencias de las oligarquías se mostraron en toda su crudeza". ${ }^{3}$

Así, en un contexto internacional poco favorable a los procesos democratizadores, la propuesta reformista de la Segunda República se vio atacada internamente desde ambos extremos del espectro político, por corrientes revolucionarias de base proletaria y por fuerzas sociales conservadoras que se oponían a la modernización socioeconómica -con la consecuente pérdida de sus privilegios- y a la ideología laicista que estaban en la base del reformismo republicano.

Sin embargo, la conflictividad política violenta producida durante la Segunda República y la guerra civil fue común en todo el continente europeo en el periodo de entreguerras, y respondió a la expansión de culturas políticas que legitimaban su culto político y la incitación al exterminio del enemigo ${ }^{4}$. La característica diferencial de España frente a otros países europeos es que la resolución de ese conflicto tripolar se produjo mediante una guerra civil, porque ninguno de los proyectos presentes tenía el apoyo de una masa social suficiente y coherente y, por tanto, fueron todos incapaces de establecer una nueva hegemonía. Pero en la primavera de 1936 no había en España ni siquiera una situación de emergencia semejante a la que vivieron otros países europeos, como

${ }^{2}$ Las citas en Aróstegui, Julio, Por qué el 18 de julio..., op. cit., pág. 292; y Graham, Helen, “Writing Spain’s Twentieth Century in (to) Europe", en Graham, Helen (ed.), Interrogating Francoism. History and Dictatorship in Twentieth-Century Spain, Londres, Bloomsbury, 2016, págs. 1- 24, pág. 1

${ }^{3}$ Aróstegui, Julio, "De la Monarquía a la República: una segunda fase en la crisis española de entreguerras", en Morales Moya, Antonio y Esteban de Vega, Manuel (Eds.), La historia contemporánea en España (Primer Congreso de Historia Contemporánea de España, Salamanca, 1992), Salamanca, Universidad, 1996, págs. 145-158, pág. 148; e "Introducción: 'España, República de trabajadores”', en Aróstegui, Julio (Ed.), La República de los trabajadores. La Segunda República y el mundo del trabajo, Madrid, Fundación Francisco Largo Caballero, 2006, págs. 50-61, pág. 60.

${ }^{4}$ Del Rey, Fernando y Álvarez Tardío, Manuel (Eds.), Políticas del Odio. Violencia y crisis en las democracias de entreguerras, Madrid, Tecnos, 2017 y Mazower, Mark, La Europa Negra. Desde la Gran Guerra hasta la caída del comunismo, Barcelona, Ediciones B, 2001. En su interpretación del fascismo europeo, Traverso plantea que éste intentó introducir en la lucha política el lenguaje y los métodos de combate experimentados, y que la guerra total banaliza la violencia y brutaliza a las sociedades. Traverso, Enzo, "Interpretar el fascismo. Notas sobre George L. Mosse, Zeev Sternhell y Emilio Gentile", Ayer, Madrid, nº 60, 2005, págs. 227-258. 
Francia: la guerra civil no estaba preinscrita en la historia de España y mucho menos, en la de la República.

\section{La república modernizadora y la génesis de la Guerra Civil española}

Tras el fracaso de la Dictadura de Miguel Primo de Rivera (1923-1930), unas elecciones municipales, convertidas en un plebiscito sobre monarquía o república, permitieron que el 14 de abril de 1931 se proclamase la Segunda República en España. El rey Alfonso XIII de Borbón abandonó el país y un Gobierno Provisional, de pequeña burguesía, intelectuales, miembros del Partido Socialista Obrero Español (PSOE), y representantes de la burguesía media a través de Derecha Liberal Republicana, se hizo cargo del poder con gran júbilo de la mayoría del pueblo español que depositó en el cambio de régimen sus esperanzas en nuevas expectativas de vida. La pregunta que surge entonces es: ¿Por qué una fiesta popular se transformó en el plazo de un quinquenio en tragedia, en guerra civil? ${ }^{5}$. La respuesta, necesariamente, remite al compromiso de modernización adoptado por la República, que pronto puso al descubierto los diversos frentes de combate, de obstrucción cuando no de incumplimiento, que los sectores sociales y las instituciones más conservadoras irían desplegando al compás de la legislación republicana más reformista y transformadora de la realidad social y política. El nuevo régimen puso en marcha un proceso de "reformismo masivo" que, según el profesor Aróstegui: "careció, tal vez, de orden y de prioridades claramente pensadas y dispuestas para su ejecución", y tuvo "grandes carencias de diseño y de instrumentación”. La coalición que llegó al poder no había diseñado nunca un verdadero "programa de gobierno". Y estas reformas, al carecer de "definición estricta de las prioridades, de un diseño eficiente del ritmo con el que las reformas habían de ser implementadas y desarrolladas, de una eficiente coordinación", también fomentaron "la progresiva resistencia que en los estratos hasta entonces ligados de forma más plena al poder oligárquico en la sociedad de la Restauración hasta 1931 despertaron las variadas disposiciones reformadoras" $"$.

En efecto, el nuevo régimen se caracterizó por poner en marcha una política reformista tendente a modernizar prácticamente todas las estructuras políticas, sociales y económicas en un ambicioso proyecto: Estado integral (con reconocimiento de autonomías), reformas del Ejército y de la Iglesia; laicismo en cultura y en educación; cambio en la estructura de la propiedad de la tierra en el campo español, derechos de la mujer... Esta política quedó reflejada en la amplia labor legislativa de los gobiernos del primer bienio, reanudada a partir de febrero de 1936. Esta legislación no sólo dibujó una democracia política garante de las libertades en que se basaba el régimen, sino también un sistema social que se sustentaba en gran medida en el compromiso de mejorar las condiciones de vida de las clases más desfavorecidas. No era un proyecto revolucionario, sino reformista, que, en muchos aspectos seguía las políticas reformadoras y democratizadoras que llevaban desarrollándose en otros países de Europa Occidental desde bastantes décadas atrás y/o desde el final de la Primera Guerra Mundial. Pero fue un intento de cambio que generó resistencias internas y externas. Josep Fontana plantea que la causa de las izquierdas, del reformismo, estaba juzgada antes de la insurrección militar,

${ }^{5}$ Juliá, Santos, Madrid 1931-1934: De la fiesta popular a la lucha de clases, Madrid, Siglo XXI, 1984.

${ }^{6}$ La primera cita, en Aróstegui, Julio, "La República. Esperanzas y decepciones”, en Tuñón de Lara, Manuel (coord.), La guerra civil española, Barcelona, Folio, 1996, vol. 1. págs. 10-58, pág. 44; las demás, en Aróstegui, Julio, "Introducción: 'España, República de trabajadores"', op. cit., págs. 56-57. 
poniendo como ejemplo la hostilidad de los medios financieros internacionales (IT'T, Rio Tinto, Banca Morgan...) al proceso reformista ${ }^{7}$.

Una de las transformaciones republicanas más discutidas, que incluso serviría en el futuro a los sublevados en 1936 para justificar su acción ante la supuesta ruptura de la unidad de España, remitía a la polémica secular Estado unitario-Estado federal. Se buscó una solución transaccional representada por el "estado integral": un Estado unitario ampliamente descentralizado compatible con la autonomía de los municipios y de las regiones, fórmula jurídica a través de la cual se canalizarían los Estatutos de autonomía de Cataluña y el País Vasco. Precisamente la reacción frente a la Sanjurjada (primer golpe de estado fracasado contra la República, liderado en agosto de 1932 por el general José Sanjurjo) permitió la aprobación del Estatuto de Autonomía de Cataluña en septiembre de 1932, y durante la guerra civil, en octubre de 1936, se procedió a aprobar el vasco. Galicia no llegaría a contar con su respectivo Estatuto de Autonomía, pese al plebiscito realizado en junio de 1936.

La Constitución republicana, aprobada en diciembre de 1931, definía a España como "una República

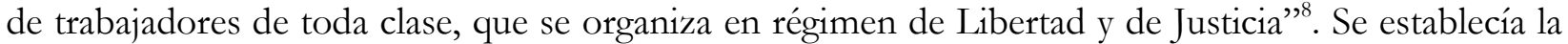
igualdad jurídica de todos los españoles, el acatamiento a las normas de Derecho Internacional, la aconfesionalidad del Estado y el español como único idioma oficial. La República se caracterizó por un sistema electoral que favorecía las coaliciones y un pluralismo fragmentado: muchos partidos divididos entre sí por hondas diferencias ideológicas e incapaces de proporcionar mayorías parlamentarias estables. Estos partidos, en la mayoría de los casos, como apuntó hace años Santos Juliá, se presentaban como portadores de proyectos contradictorios de sociedad y Estado: socialistas, católicos, comunistas, monárquicos, fascistas, llevaban en sus programas modelos excluyentes de sociedad y propuestas de Estado en las que sus adversarios políticos estaban condenados a desaparecer o a ser liquidados? .

Por lo que respecta a la problemática educativa, hay que señalar que la tasa de analfabetismo en España alcanzaba el 45\% de la población en 1930. Los republicanos quisieron desde el principio extender la cultura a las clases más desfavorecidas, como una forma de acabar con el atraso social de España y de potenciar su modernización. Además, los ideales educativos republicanos tenían como objetivos la socialización de la cultura, la igualdad ante la educación y la instauración de la escuela única, pública, que sustituyese a la religiosa ${ }^{10}$. Pero eran unos ideales que chocaban con la hegemonía que hasta entonces había detentado la Iglesia católica en la enseñanza. Además, el laicismo constitucional sería desbordado en anticlericalismo en junio de 1933 cuando, a través de la Ley de Confesiones y Congregaciones Religiosas, se prohibió el ejercicio de la enseñanza a las órdenes religiosas.

Una parcela muy importante de la labor reformista y modernizadora que desarrolló el Estado republicano fue la referida a la legislación socio-laboral y la reforma agraria, sobre todo por la acción desplegada por el socialista Francisco Largo Caballero desde el Ministerio de Trabajo (desde abril de 1931 hasta septiembre de 1933). Eran reformas pragmáticas y que no tenían carácter revolucionario,

\footnotetext{
7 Fontana, Josep, "La Segunda República: una esperanza frustrada”, en Fontana, J. et al.: La II República. Una esperanza frustrada. Actas del congreso Valencia Capital de la República, Valencia, Ed. Alfons El Magnànim, 1987, págs. 9-22.

8 Pérez Ayala, Andoni: "La Constitución republicana de 1931 siete décadas después", Cuadernos Republicanos, Madrid, nº 49, (2005), págs. 13-34.

9 Juliá, Santos, El País, Madrid, 11/4/1991.

10 González Martínez, Carmen, "Redimir a España por la escuela: la comprometida apuesta de la II República y sus maestros. La experiencia en Murcia, en Salmerón, Francisco, et al., Maestros republicanos en Murcia. Un intento de transformación de la Escuela, Murcia, ICE-DM2007, págs. 39-48.
} 
aunque si intervencionista, ya que el Estado intervendría directamente en las relaciones laborales. En muchos casos seguían, casi por primera vez en España, las directrices emanadas desde la Organización Internacional del Trabajo, intentando crear un sistema completo de relaciones laborales ${ }^{11}$ : jornada laboral de 8 horas y fijación del salario mínimo, ley de Contrato de Trabajo, ley de colocación obrera, libertad de asociación sindical y patronal, Ley de Accidentes de Trabajo en la Industria; seguro de maternidad -aunque fue imposible crear un seguro contra el desempleo-, y la norma estrella del primer bienio reformista: la Ley de Jurados Mixtos de noviembre de 1931 (de trabajo rural e industrial), organismos encargados de regular las negociaciones colectivas, con unas funciones muy amplias y representación patronal y obrera, que legislaron las más de las veces a favor de los trabajadores. Toda esta nueva legislación fue cuestionada por la patronal, pero también por el anarcosindicalismo de la Confederación Nacional del Trabajo (CNT), que rechazó los Jurados Mixtos por su defensa de la relación directa entre patronos y obreros, lo que favoreció, aún más, el papel del sindicato socialista Unión General de Trabajadores (UGT) en éstos. Sin embargo, los Jurados Mixtos permitieron, en la mayoría de los casos, una salida legal a la conflictividad social del periodo.

En vísperas de la República, según el censo de 1930, la población española alcanzaba la cifra de 23.677.095 habitantes, de los que 9 millones eran población activa, mayoritariamente empleados en la agricultura (3.900.000) y, de éstos, 1.900 .000 eran asalariados agrarios. Dada esta caracterización del país, con una economía predominantemente agrícola, las reformas laborales que afectaron al obrero agrícola adquirieron gran importancia, casi más que la reforma agraria, dado que afectaban a todo el Estado: ley de términos municipales y de laboreo forzoso; arrendamientos colectivos a los obreros campesinos organizados en asociaciones sindicales; ley de accidentes de trabajo en la agricultura; jornada máxima de 8 horas en el campo; obligatoriedad de pagar las restantes como horas extraordinarias...La Ley de Bases de la Reforma Agraria, aprobada en septiembre de 1932, fracasó en su intento de crear un gran número de pequeñas propiedades campesinas, ya que a fines de 1933 tan sólo se habían expropiado en torno a 89.000 hectáreas, que permitieron el asentamiento de 8.600 familias, cuando la Ley preveía un asentamiento anual de 60.000 campesinos. La escasa incidencia de esta política de reforma agraria llevó el conflicto campesino en las zonas latifundistas del sur de la península a extremos cada vez más violentos, como muestran las insurrecciones anarquistas de enero y diciembre de 1933, pero también sembró de una altísima conflictividad sociolaboral el campo español más allá del latifundio durante todo el primer bienio republicano. Además, en España no había una clase capitalista fuerte que pudiese responder con las concesiones necesarias a la efectividad de tales reformas y aquella mantenía su capital afincado en lugares más seguros ${ }^{12}$. Por otro lado, los años treinta estuvieron acompañados de una crisis económica que dejó sentir sus efectos en España en 1933. La erosión en los niveles de vida y el paro constituyeron un fuerte estímulo para la acción huelguística, por lo que la frustración derivó en protesta social, y, en el caso del anarcosindicalismo, dio lugar a acciones insurreccionales en 1932 y 1933 que, si bien fracasaron, erosionaron la legitimidad de la República.

Las tensiones internas de la coalición gobernante y los crecientes problemas en la aplicación de las reformas, con su correlato de conflictividad social, llevaron a la ruptura de la coalición republicanosocialista. Las elecciones generales celebradas en noviembre de 1933 dieron el triunfo al centrista

11 González Martínez, Carmen, "Relaciones labores en Murcia durante la experiencia republicana: actitudes y conflictos", Historia Social, Valencia, no 33, 1999, págs. 73-95. Aróstegui, Julio, Largo Caballero. El tesón y la quimera, Madrid, Debate, 2013.

12 Fontana, Josep, "La Segunda República...”, op. cit; Puche Gil, Javier, Más allá del latifundio. Conflictividad rural y bienestar biológico en Yecla durante la II República, Alzira, Germanía, 2013. Casanova, Julián, "España, 1931-1939: República, protesta social y revolución", en Julio Valdeón, et al., Revueltas y revoluciones en la Historia, Salamanca, Universidad de Salamanca, 1990, págs. 135-150. 
Partido Radical, dirigido por Alejandro Lerroux, y a la CEDA (Confederación Española de Derechas Autónomas, el partido de masas organizado por las clases conservadoras y católicas que mantenía una defensa del "accidentalismo" de las formas de gobierno), liderada por José María Gil Robles. Se inició así el segundo bienio republicano -el bienio rectificador o radical-cedista- que impuso una paralización, cuando no una clara obstrucción, a las políticas modernizadoras iniciadas en el bienio anterior. En líneas generales, los gobiernos de centro derecha buscaron dar marcha atrás en la política reformista de Manuel Azaña, el intelectual y dirigente más importante de la izquierda republicana, con la idea de "rectificar" la República: desde 1934 hubo un gran número de disposiciones encaminadas a revisar las reformas emprendidas en el primer bienio, aunque según planteó en su día Tusell, hay argumentos para juzgar que no toda la obra del segundo bienio fue contraproducente desde el punto de vista social. Así, durante el período en que fue ministro de Agricultura Cirilo del Río, el número de campesinos instalados superó al del primer bienio (6.300). A partir de octubre, su sustituto, Manuel Giménez Fernández, no sólo siguió aplicando la ley, sino que prolongó una medida que había sido totalmente rechazada por la derecha: los decretos de intensificación de cultivos. Consiguió también la aprobación de una nueva ley de arrendamientos, en absoluto desdeñable para quienes militaban en grupos republicanos de izquierda. Es cierto, sin embargo, que gran parte de su labor fue obstaculizada por miembros de su propio partido y que, en julio de 1935, vería la luz la contrarreforma agraria, con la que se producía una drástica disminución de los propósitos de los legisladores del primer bienio por el procedimiento de reducir al mínimo las disponibilidades económicas del IRA. ${ }^{13}$

El 4 de octubre, el gobierno presidido por Lerroux dio entrada a 3 ministros de la CEDA y los socialistas llamaron a una huelga general revolucionaria, considerando que la entrada de la coalición católica en el gobierno significaba la entrega de la República a sus enemigos: una "revolución preventiva" frente al fascismo ya instalado en otros países europeos, según Marta Bizcarrondo, aunque el modelo de Gil Robles era más cercano al canciller católico austríaco Engelbert Dollfuss, que había establecido una dictadura autoritaria en el país alpino, que al fascismo propiamente dicho. ${ }^{14}$

Se produjeron en España dos procesos revolucionarios diferenciados y con una gran variedad de manifestaciones regionales y locales. Por un lado, la iniciativa socialista que se inició en la madrugada del 4 al 5 de octubre. Esta acción tuvo diferentes efectos y formas en las distintas provincias -desde la huelga pacífica a la insurrección y la revolución social- según la fuerza, organización, posición política y táctica no solo de las organizaciones que participasen sino en función de las mismas diferencias internas dentro de las organizaciones socialistas, divididas entre la minoritaria derecha representada por Julián Besteiro, el centrismo socialista encabezado por Indalecio Prieto, y la izquierda, liderada por Francisco Largo Caballero. ${ }^{15}$ Por otro lado, se produjo la proclamación de un Estat Catalá por parte del gobierno de la Generalitat de Cataluña, presidido por Lluis Companys, líder de Esquerra Republicana de Catalunya. El movimiento distó de tener una organización que unificara

\footnotetext{
13 Tusell, Javier, Manual de Historia de España. Siglo XX, Madrid, Historia 16, 1990.

14 Bizcarrondo, Marta, Octubre del 34: reflexiones sobre una revolución, Ayuso, Madrid, 1977; Souto Kustrín, Sandra, "De la paramilitarización al fracaso: las insurrecciones socialistas de 1934 en Viena y Madrid", Pasado y Memoria, Alicante, nº. 2, 2003, págs.193-220; González Martínez, Carmen y Souto Kustrín, Sandra, "Por el Estado/contra el Estado: las milicias políticas en el primer tercio del siglo XX", en Ruiz Ibáñez, José Javier (Coord.), Las milicias del Rey de España. Sociedad, politica e identidad en las Monarquias ibéricas, Madrid, FCE, 2009, págs. 481-515.

${ }^{15}$ Véase, por ejemplo, Marta Bizcarrondo, "Democracia y revolución en la estrategia socialista de la Segunda República", Estudios de Historia Social, Madrid, n’. 16-17 (enero-junio 1981), págs. 227-461; o Juliá, Santos, 1931-1939, en Manuel Tuñón de Lara (Dir.), Historia del Socialismo Español, vol. 3. Barcelona, L’Avenç, 1989.
} 
a las diferentes organizaciones obreras. El instrumento de unidad, la Alianza Obrera, sólo había logrado la participación de la CNT en Asturias, donde se produjo una verdadera revolución social. Octubre de 1934 evidenció la incapacidad de los socialistas de tomar el poder por la vía revolucionaria, ajena a su tradición de actuación basada en el legalismo y el reformismo ${ }^{16}$.

Y fue el fracaso de 1934 el que convenció al proletariado organizado de que la vía revolucionaria no era aplicable y fue su "más fértil fuente de reflexiones" sobre la estrategia a seguir en el futuro, dando lugar a la aparición de nuevas fórmulas reformistas. Esto no supone negar que los sucesos de octubre produjeron también, "como reacción, la agudización contrarrevolucionaria de los grupos más conspicuos de la derecha española". ${ }^{17}$ Tras el ascenso de los nazis al poder en Alemania, la derrota de la socialdemocracia austríaca en febrero de 1934 y la de la española en octubre, y con el precedente del pacto de unidad de acción entre socialistas y comunistas en Francia, el llamamiento a la unidad de la clase obrera contra el fascismo y la estrategia interclasista de movilización de masas para la defensa de la 'democracia burguesa' formuladas por Jorge Dimitrov y aprobadas en el VII Congreso de la Internacional Comunista o Komintern (julio-agosto 1935), ejerció una exitosa atracción en toda la izquierda europea, no solo la española, especialmente entre los más jóvenes ${ }^{18}$.

En España, el fracaso de Octubre y la consiguiente represión facilitó la formación del Frente Popular, con un programa moderado que era una continuación de las reformas del primer bienio, y que supuso la ampliación de la coalición electoral republicano-socialista que había gobernado en el primer bienio a las demás organizaciones obreras, favorecida por el fraccionamiento del PSOE, que dio una mayor capacidad de actuación a los otros partidos obreros y la hegemonía a los republicanos. ${ }^{19} \mathrm{El}$ Frente Popular ganó las elecciones de febrero de 1936 frente a las derechas, encabezadas por la CEDA, cuya consigna fue "contra la revolución", representando ambos bloques dos concepciones distintas del Estado y la sociedad.

El triunfo del Frente Popular en las elecciones de febrero (278 diputados frente a 130 de las derechas), llevó a la formación de un gobierno de la izquierda republicana y, ya en mayo de 1936, el presidente de la República, Niceto Alcalá Zamora, fue sustituido por Azaña. Y fue el triunfo del Frente Popular el que espoleó a las derechas hacia el camino insurreccional, al considerar que la defensa de sus intereses no podía lograrse sin la recuperación violenta del poder político ${ }^{20}$. Sin embargo, en la España de 1936 no había ningún plan de revolución del proletariado y mucho menos, de sectores sociales caracterizados políticamente como de izquierdas; por el contrario, fue la sublevación militar del 18 de julio y el fracaso de los objetivos inmediatos que se proponía lo que provocó un proceso revolucionario en España. Esto no implica negar la presencia de discursos y

${ }^{16}$ Souto Kustrín, Sandra, "Y ¿Madrid? ¿Qué hace Madrid?". Movimiento revolucionario y acción colectiva (1933-1936), Madrid, Siglo XXI, 2004 y «Octubre de 1934: historia, mito y memoria», en Prada Rodríguez, Julio y Grandío Seoane, Emilio F., (coords.), «La Segunda República: Nuevas miradas, nuevos enfoques», Hispania Nova, n. ${ }^{\circ} 11$ (2013), 33 págs.; López Esteve, Manel, Els fets del 6 d'octubre de 1934 (prólogo de Josep Fontana), Barcelona, Base, 2013.

17 Aróstegui, Julio, "Una izquierda en busca de la revolución [El fracaso de la segunda revolución]", en Sánchez Pérez, Francisco et alt, Los mitos del 18 de Julio, Barcelona, Crítica, 2013, págs. 183-220, pág. 203.

${ }^{18}$ Dimitrov, Jorge, Escritos sobre el fascismo: selección de textos, Madrid, Akal, 1976. Souto Kustrín, Sandra, "La atracción de las Juventudes Socialistas por el PCE en el contexto europeo de los años treinta", en Bueno, Manuel, Hinojosa, José y García, Carmen (Coords.), Historia del PCE. I Congreso 1920-1977, Madrid-Oviedo, FIM-Universidad de OviedoPrincipado de Asturias-Fundación Juan Muñoz Zapico, 2007, 2 vol., vol. 1, págs. 113-127.

${ }^{19}$ Juliá, Santos, Orígenes del Frente Popular en España (1934-1936), Madrid, Siglo XXI, 1979, pág. 162.

20 Tuñón de Lara, Manuel, Tres claves de la II República. La cuestión agraria, los aparatos del Estado y el Frente Popular, Madrid, Alianza, 1985. 
demagogias revolucionarias y el aumento de los conflictos socio-políticos violentos en la primavera de 1936 producidos desde ciertos sectores de la izquierda y la derecha radical, que "desbordaron" en parte al gobierno, y que acentuaron también "un $<<$ miedo a la revolución $>>$ que no dejó de estar presente" y fueron amplificados y rentabilizados por las derechas y por los mismos conspiradores. ${ }^{21}$

La intervención del ejército a través del golpe militar no contemplaba una guerra, sino la conquista rápida del poder político para acabar con la República reformista y con el movimiento obrero. Pero el colapso del Estado republicano no fue total, hubo importantes sectores de las fuerzas armadas y de seguridad que no secundaron el golpe y se produjo una importante movilización popular que coadyuvó a hacerlo fracasar en importantes ciudades, como Madrid y Barcelona. El fracaso de la sublevación dio paso a una guerra civil y al inicio de una segunda revolución, pero esto no implica que se pueda definir la guerra como revolucionaria, como ha hecho recientemente Stanley Payne, porque "la sublevación perfiló definitivamente las condiciones para el desencadenamiento de una revolución real, pero inhibió, igualmente, la amplitud del espectro y del horizonte en que se movían ciertos discursos revolucionarios precedentes", no fue apoyada por todos los sectores obreros y tampoco tenía un proyecto coherente y único, aunque llevaría a un debate constante en la zona republicana en torno al binomio guerra-revolución. ${ }^{22}$

La rebelión militar creó un vacío de poder en la zona republicana y favoreció la proliferación de juntas, comités y consejos que disputaron el poder al gobierno central. Esta situación de soberanía múltiple, de poderes autónomos, remite, según Rafael Cruz, a la coexistencia de tres grandes organismos con el poder de dirigir los asuntos públicos en cada ciudad o territorio: un Consejo o Comité Central Antifascista a escala provincial o regional, integrado por los sindicatos y los partidos de la coalición de izquierdas, en diversas proporciones según su implantación local; una o varias instituciones del Estado, en general integradas por el Gobierno Civil, los ayuntamientos y los destacamentos del Ejército Popular de la República, y uno o varios comités locales con diferentes nombres y plena autonomía. Los enfrentamientos entre estas tres instancias fueron tan frecuentes como la negociación y la ignorancia mutua de sus actividades respectivas. ${ }^{23}$

Las vacilaciones de los republicanos en el gobierno en julio de 1936 -que temían tanto o más que el golpe militar de signo antirrepublicano, el desbordamiento del orden social por obra de una acción de masas- y el importante papel jugado por las fuerzas obreras en la derrota de la sublevación, dificultaba, si no impedía, la vuelta en la zona republicana a la situación previa al 18 de julio, especialmente en relación con las fuerzas en presencia en el gobierno, y llevaron, en septiembre, a la formación de un ejecutivo dirigido por el líder sindical socialista Largo Caballero, en el que participaron miembros del Partido Nacionalista Vasco (PNV), cuyo principal dirigente, José Antonio Aguirre, sería nombrado primer presidente del gobierno autónomo del País Vasco el 8 de octubre de 1936, y al que en noviembre de 1936 se incorporó la CNT. En Cataluña, se formó un nuevo gobierno, incluyendo a la CNT y al Partido Obrero de Unificación Marxista (POUM) -comunistas antiestalinistas- el 26 de septiembre.

\footnotetext{
21 Aróstegui, Julio, “Una izquierda en busca...”, op. cit., pág. 206.

22 Casanova, Julián, "España, 1931-1939...”, op. cit. La cita, en Aróstegui, Julio, “Una izquierda en busca...”, op. cit., pág. 187. Payne, Stanley, La Europa revolucionaria. Las guerras civiles que marcaron el siglo XX, Madrid, Temas de Hoy, 2011.

23 Cruz, Rafael, En el nombre del pueblo. República, rebelión y guerra en la España de 1936, Madrid, Siglo XXI, 2006, pág. 282. Destacarían por su importancia el Consejo de Asturias-León y el de Aragón, este último, de preponderancia anarquista.
} 
Otro factor que convirtió una sublevación fracasada en una guerra de casi tres años fue la intervención internacional y, en primer y definitivo lugar, la de las potencias fascistas, dado que la Unión Soviética hubiera preferido una política de neutralidad. Sin el auxilio de las primeras los sublevados no hubieran podido persistir en su intento de apoderarse del poder en los últimos días de julio de 1936 y sin la intervención internacional ninguno de los dos bandos militares hubiera podido mantener una guerra larga. El abandono de las potencias democráticas convirtió a la URSS en el único apoyo real a la República, junto con el del lejano México y los voluntarios internacionales antifascistas, mayoritariamente agrupados en las Brigadas Internacionales. Como dice Ricardo Miralles, la República cultivó la relación con la URSS porque de ella dependía el suministro básico de armas, pero su futuro nunca dependió, en términos diplomáticos, de la Unión Soviética "-cosa que advirtió muy pronto Stalin, que hubiera preferido la neutralidad, a Largo Caballero-, sino del complejo sistema de la no intervención diseñado por los franceses, pero explotado sustancialmente por los ingleses" ${ }^{\prime 24}$.

Las potencias europeas tomaron postura, basándose en muchos casos, según Ucelay da Cal, en ideas preconcebidas y estereotipos en torno a las interpretaciones de la guerra civil española ${ }^{25}$. Pero más allá de del choque de estados y gobiernos, "la primera ronda de un enfrentamiento europeo para determinar el futuro de la sociedad y la política en todo el continente", la guerra civil implicó a muchos ciudadanos, "cuyo impacto entendieron claramente como un punto de inflexión continental". La idea de cruzada de Franco encontró una audiencia receptiva entre sectores conservadores no solo por las matanzas anticlericales que se produjeron en el verano de 1936 en la zona republicana, sino porque podían ver en sus países grupos sociales que no eran contenibles en las estructuras políticas y sociales tradicionales: "Se debe entender la resonancia de la guerra de España para los conservadores a lo largo y ancho de Europa" porque la consideraron "una guerra para defender las estructuras conocidas de poder". De la misma manera, al venir a combatir al fascismo en España, los brigadistas estuvieron influenciados por la ola de ultraconservadurismo y por la crisis económica que habían vivido personalmente: sentían que al venir a combatir a España contra los militares sublevados y los regímenes fascistas que le apoyaban también estaban propinando un golpe a la opresión económica y política de sus países, entre ellos, muchos judíos. ${ }^{26}$

Fue la situación en que se generó la guerra y las características de ésta las que determinaron en gran parte la evolución de ambos bandos enfrentados, evolución que a la vez influyó en el desarrollo mismo de la guerra. Los sublevados solo estaban de acuerdo en lo negativo: en el derribo inmediato del gobierno del Frente Popular. Todas las organizaciones de las derechas (fascistas de Falange Española de las Juntas de Ofensiva Nacional Sindicalista (JONS), los carlistas de la Comunión

\footnotetext{
${ }^{24}$ La cita, en Miralles, Ricardo, Juan Negrín. La República en Guerra, Madrid, Temas de Hoy, 2003, pág. 254. Véase la completa trilogía de Viñas, Ángel, La soledad de la República. El abandono de las democracias y el viraje hacia la Unión Soviética, Barcelona, Crítica, 2006; El escudo de la República. El oro de España, la apuesta soviética y los hechos de mayo de 1937, Barcelona, Crítica, 2007; y El honor de la República: entre el acoso fascista, la hostilidad británica y la política de Stalin, Barcelona, Crítica, 2009.

${ }^{25}$ Ucelay da Cal, Enric, "Ideas preconcebidas y estereotipos en las interpretaciones de la guerra civil española: el dorso de la solidaridad", Historia Social, no 6, invierno 1990, págs. 23-43.

${ }^{26}$ Graham, Helen, “Writing Spain’s...”, op. cit., págs.1 y 4. Desde el 7 de noviembre de 1936 hasta el 15 de diciembre de 1938, en torno a 40.000 brigadistas internacionales lucharon a favor de la República, con 18.000 bajas, contabilizándose voluntarios de más de 35 países. Crusells, Magí, Las Brigadas Internacionales en la pantalla, Universidad de Castilla-La Mancha, Ciudad Real, 2002. Ibáñez Sperber, Raquel, "Judíos en las Brigadas Internacionales. Algunas cuestiones generales”, Historia Actual Online (HAOL), Cádiz, no 9 (invierno 2006), págs.101-115. Requena Gallego, Manuel y Prades Artigas, Lourdes M., "Las Brigadas Internacionales. Mayor presencia y renovación en la bibliografía sobre la Guerra Civil”, en Viñas, Ángel y Andrés Blanco, Juan (Dirs.), La Guerra Civil española, una visión bibliográfica, Madrid, Marcial Pons Historia Digital, 2017, págs. 210-243.
} 
Tradicionalista -defensora de la rama carlista de los Borbones-; y monárquicos alfonsinos, partidarios de Alfonso XIII), colaboraron con los militares, y cada una de estas fuerzas políticas tenía su propio proyecto, que no era en ningún caso un régimen liberal. La proclamación desde un primer momento del Estado de guerra -el gobierno republicano no lo establecería hasta enero de 1939- determinó la transferencia de todo el poder a los militares. La llamada Junta de Defensa Nacional de España, con sede en Burgos, a través de los decretos de 13 de septiembre y de 25 de septiembre de 1936, declaró fuera de la ley a todos los partidos y agrupaciones políticas del Frente Popular, la incautación de sus bienes muebles e inmuebles, pasando a la propiedad del incipiente "Estado Nacional", así como la prohibición de toda actividad política y sindical de las organizaciones obreras y patronales. ${ }^{27}$

En la zona bajo el control del gobierno republicano legítimo, el cambio revolucionario iniciado en julio de 1936 no llegó a consumarse enteramente y entró en un declive que culminó el 17 de mayo de 1937, cuando, tras los sucesos producidos en Barcelona unas semanas antes -influidos, entre otros factores, por el control de centros importantes, como la Telefónica, por las organizaciones anarcosindicalistas- a Largo Caballero le sustituyó en la presidencia de gobierno el también socialista Juan Negrín, propuesto por la Comisión Ejecutiva del PSOE con el acuerdo de Azaña. Este gobierno contaba con representantes de todos los partidos republicanos, centristas del PSOE y comunistas, pero no de los sindicatos ${ }^{28}$. Estos sectores confluyeron en la necesidad de una centralización de la economía y de un mando único, así como de recabar la ayuda de las potencias democráticas para intentar ganar la guerra. El gobierno de Negrín buscó la reconstrucción del Estado mediante la centralización de los poderes políticos y económicos en el gobierno de la República, el restablecimiento de un funcionamiento regular de las instituciones democráticas republicanas, la restauración del orden público, la reconstrucción del ejército y la centralización de las decisiones militares. En estas circunstancias, el importante papel jugado por el PCE no se debió sólo a los privilegios de su relación con la URSS, sino que estuvo influido por su capacidad organizativa, su disciplina, su comprensión de las necesidades del esfuerzo de guerra y de que éste requería una movilización popular y su capacidad de realizarla, frente a la división creciente del PSOE y la debilidad de los republicanos. ${ }^{29}$

La continuación del esfuerzo de guerra bajo la consigna de Negrín de "resistir es vencer", acabó alejando al mismo Azaña del gobierno de la República. Pero nadie formuló otra política, probablemente, porque "no había otra política posible", y, "cuando por fin alguien se decidió a impugnar su consigna de resistir a ultranza sólo pudo hacerlo desde la sedición, porque no otra cosa fue el golpe de Casado", que no conseguiría una paz honrosa sino una simple capitulación que favoreció la intensa represión de posguerra. Como sintetizó muy acertadamente el profesor Julio

\footnotetext{
27 Reig Tapia, Alberto, Memoria de la Guerra Civil. Los mitos de la Tribu, Alianza Editorial, Madrid, 1999. La Ley de Responsabilidades políticas promulgada por Franco el 9 de febrero de 1939 sería otro instrumento más para el ejercicio de la represión una vez finalizada la contienda.

${ }^{28}$ La CNT volvería al gobierno en abril de 1938. El anarcosindicalismo sufrió importantes cambios y tensiones con la guerra, aunque, como dice Casanova, Julián, De la calle al frente. El anarcosindicalismo en España (1931-1939), Barcelona, Crítica, 1997, págs. 227-228, "los signos tanto de transformación como de división del anarcosindicalismo estaban presentes ya en los años republicanos".

${ }^{29}$ Gallego, Ferrán, Barcelona, mayo de 1937. La crisis del antifascismo en Cataluña, Barcelona, Debate, 2007; Graham, Helen, The Spanish Republic at War..., op. cit., y El PSOE en la Guerra Civil. Poder, crisis y derrota, Barcelona, Debate-Random House Mondadori, 2005. Ver también Moradiellos, Enrique, Negrín, Barcelona, Península, 2006.
} 
Aróstegui: "La experiencia republicana no desembocó en guerra civil, sino que fue destruida con la guerra" $"$.

Cuando las tropas de Franco avanzaron sobre Cataluña, miles de españoles, temerosos de la represión violenta franquista, cruzaron los Pirineos marchando a un exilio incierto. Mujeres, niños, ancianos y combatientes, hambrientos y mal vestidos, se amontonaron en campos de internamiento habilitados por las autoridades galas. ${ }^{31}$ Un símbolo de todos ellos fue Antonio Machado, que murió 'solo y ligero de equipaje' en un hotelito de Collioure, pueblo fronterizo próximo al mar, el 22 de febrero de 1939.

\section{La historiografía sobre la guerra civil. Aportaciones al debate desde Contenciosa.}

La guerra civil española, tanto por el impacto que tuvo en todo el ámbito europeo como por su resultado de casi 40 años de una dictadura que trató de imponer su propia versión de los hechos, ha sido tradicionalmente estudiada por hispanistas extranjeros. Baste recordar el papel clave que tuvieron las historias de la guerra civil elaboradas por Hugh Thomas (1961) o Gabriel Jackson (1967) en los inicios de una historiografía seria sobre ella.

Ahora, la guerra de España sigue interesando a investigadores de diferentes países. Sin embargo, como dice Enrique Moradiellos, desde el cincuentenario de la guerra civil los estudios y debates "han permitido avances sustanciales en la tentativa de comprensión historiográfica", arrumbando "sin remisión las visiones más simplistas sobre la contienda, a favor de esquemas interpretativos más pluralistas y complejos". ${ }^{32}$ La historiografía española ha alcanzado una madurez que hace que ya no sea subsidiaria de las investigaciones realizadas por extranjeros, lo que no quiere decir que éstos no hayan aportado y sigan aportando investigaciones importantes, como se refleja en las mismas referencias que acompañan esta introducción.

Entre la opinión pública suscita debates y reacciones diversas. Durante la transición a la democracia, la memoria que operó fue la de la guerra civil que funcionó como imagen negativa y a la que se asoció la experiencia republicana. Tanto la imagen como la memoria de la República fueron condicionadas por su final trágico en una guerra civil y se mantuvo la idea de fracaso de la República, que llevaba en algunos casos a análisis reduccionistas y que permitía desligar "el régimen franquista (...) del propio proceso de guerra civil del que surgió", pero que fue rápidamente rechazada por los historiadores desde el trabajo seminal de Santos Juliá de 1981: la guerra civil no se origina en un "presunto fracaso de la República, sino en el fracaso de un golpe de Estado cuya finalidad consistía en hacer fracasar algunas vías abiertas por la República para construir un nuevo marco de relaciones sociales y políticas en España”. Sin embargo, a pesar de que el socialismo fue uno de los soportes esenciales del régimen republicano, tampoco el PSOE en el poder desde 1982 promovió "una recomposición de esa imagen

\footnotetext{
30Juliá, Santos, 1931-1939, Juliá, op. cit., pág. 202; Miralles, Ricardo, Juan Negrín..., op. cit., pág. 360. Aróstegui, Julio, "Epílogo. Memoria de la República en tiempos de transición”, en Egido León, Ángeles, Memoria de la Segunda República. Mito y realidad, Madrid, Biblioteca Nueva-Ciere, 2006, págs. 363-374, pág. 366.

31 Sevillano Calero, Francisco, La cultura de guerra del "nuevo Estado" franquista. Enemigos, héroes y caídos por España, Madrid, Biblioteca Nueva, 2017. Nicolás Marín, Encarna y González Martínez, Carmen, "Españoles en los Bajos Pirineos: Exiliados republicanos y diplomáticos franquistas ante franceses y alemanes 81936-1945)", Anales de Historia Contemporánea, Murcia, nº.17, 2001, págs. 639-660.

32 Moradiellos, Enrique, "Ni gesta heroica ni locura trágica: nuevas perspectivas históricas sobre la guerra civil", Ayer, Madrid, nº 50 (2003), págs. 11-39, pág. 24.
} 
de la República". Ni siquiera en el sesenta aniversario del comienzo de la guerra civil, en 1996, se reparó "en la identidad republicana" y fue la "derecha intelectual y política más que la izquierda" la que reabrió el debate. ${ }^{33}$

Siguen persistiendo quienes no quieren recordar este pasado o se empeñan en conservar viva la memoria de la guerra como una "cruzada", lo que ha permitido que resurjan, frente a las nuevas investigaciones, voces y libros de periodistas o pseudobistoriadores que buscan reactualizar la vieja historiografía franquista ${ }^{34}$, totalmente superada por una gran mayoría de investigaciones serias, rigurosas y documentadas. $\mathrm{Y}$ es que, en efecto, una problemática que acusan tanto la Guerra Civil española como otras de nuestro entorno europeo (caso de la italiana), es la del intrusismo en el ejercicio de la historiografía y la instrumentalización de la memoria en el presente. Así Dondi dio cuenta de la salida a la venta en 2003 del best seller del periodista Gianpaolo Pansa Il sangue dei vinti (La sangre de los vencidos), que trajo consigo la crítica de los historiadores y la comunidad académica por el uso mal contrastado de fuentes fascistas y el empleo de un lenguaje tremendista y que recordaba a los viejos libros fascistas por su punto de vista y contenidos. Dondi denunciaba además que en este siglo en que los medios de comunicación tienen un enorme poder para difundir mensajes entre la población, los periodistas sustituyan a los historiadores a la hora de interpretar el pasado, presentando una cultura devaluada ${ }^{35}$.

Este número de Contenciosa no pretende hacer un repaso exhaustivo de todas las problemáticas y todos los procesos que se vivieron en la guerra civil española en el dividido Estado español ni en ninguno de los dos bandos en conflicto y, mucho menos, ser una historia de la guerra civil. Si tradicionalmente uno de los principales problemas de la historiografía española ha sido el "escaso impulso hacia la construcción de síntesis" sobre el periodo que analizamos, este parece haberse solucionado en los últimos años ${ }^{36}$. En función de estas premisas, este monográfico recoge una selección de investigaciones realizadas por especialistas en las materias tratadas que muestran los aspectos más novedosos y/o más polémicos de la nueva historiografía sobre el conflicto, obviando temas ya suficientemente tratados por la historiografía.

El papel de la Iglesia Católica en la justificación del golpe de Estado y su conversión en "Cruzada" es uno de los que más debates ha generado y genera, a la vez que la apertura creciente de los archivos del Vaticano -del que el investigador Hilari Raguer es uno de los principales conocedores- permite matizaciones y nuevas perspectivas. Como muestra este artículo, una cosa fue la posición del episcopado español y otra la de las instituciones vaticanas. Sin negar el papel que jugaron los excesos

33 González Martínez, Carmen, Guerra Civil en Murcia. Un análisis sobre el poder y los comportamientos colectivos, Murcia, Universidad, 1999, pág. 55; Juliá, Santos, "El fracaso de la República", Revista de Occidente, Madrid, n. 7-8 (noviembre 1981), págs. 196-211, pág. 200; Aróstegui, Julio, “Epílogo...”, op. cit., págs. 369 y 373.

34 González Martínez, Carmen, " $<$ El pasado no está muerto ni es pasado>: Historiografía de la Guerra Civil y revisionismo en el año de la memoria histórica”, en Capellán de Miguel, Gonzalo y Pérez Serrano, Julio (Eds.): Sociedad de masas, medios de comunicación y opinión pública, 2 vols., Logroño, Instituto de Estudios Riojanos, 2008, vol. 1, págs. 57 - 77.

35 Dondi, Mirco, "La guerra Civil italiana: de las armas a la memoria", en Morente Valero, Francisco (Ed.), España en la crisis europea de entreguerras: república, fascismo y guerra civil, Madrid, Catarata, 2011. El libro de Pansa llegaba a equiparar a las víctimas fascistas con los 30.000 desaparecidos de la dictadura argentina de 1975-1982.

36 Pasamar, Gonzalo, La historia contemporánea. Aspectos teóricos e historiográficos, Madrid, Síntesis, 2000, pág. 248. Véase Graham, Helen, Breve historia de la guerra civil, Madrid, Espasa Calpe, 2006 (or. Oxford University Press, 2005); Casanova, Julián, España partida en dos. Breve historia de la guerra civil española, Barcelona, Crítica, 2013, o Luengo, Félix y Aizpuru, Mikel, La Segunda República y la Guerra Civil, Madrid, Alianza, 2013; y algo más amplios, Preston, Paul, La guerra civil española, Barcelona, Debate, 2006 (edición revisada y actualizada, or.1996) o Casanova, Julián, República y Guerra Civil, BarcelonaMadrid, Crítica-Marcial Pons, 2007. 
anticlericales -especialmente la violencia de los primeros meses de la guerra en la zona republicana ${ }^{37}$ en las posiciones de la Iglesia española, el trabajo del profesor Raguer muestra que ésta deseaba un golpe de Estado, aunque no participara en su organización y, con escasas excepciones, el episcopado español lo apoyó desde un primer momento. Por el contrario, los golpistas no se plantearon en un principio una rebelión con contenido religioso, pero la utilidad de la idea de Cruzada como legitimadora de una "guerra buena" les llevaría a apoyarse en la Iglesia, para lograr consenso social en las zonas que controlaban ${ }^{38}$.

Sin embargo, y a pesar de la terrible persecución religiosa, el Vaticano se resistió a reconocer al gobierno franquista. Esto queda reflejado en el discurso realizado por el papa Pio XI en Castelgandolfo, su primera expresión pública sobre la guerra, que no era una defensa de los sublevados, aunque estos en un primer momento lo publicaran mutilado para hacerlo parecer un apoyo; pero también en su prólogo a la carta colectiva de los obispos españoles que, como muestra novedosamente este artículo, el Vaticano se llegó a plantear frenar, y que también fue tergiversado por los sublevados. Ante el asesinato de sacerdotes vascos por los franquistas, el papa diría que "en la España nacional se fusilan los sacerdotes como en la España del otro lado”.

Pero el episcopado español, como muestra Hilari Raguer, aunque con algunas honrosas excepciones, se mostró inmisericorde con los que vivían en la zona republicana y con los vencidos: rechazó criticar los bombardeos indiscriminados de la población civil, rechazó apoyar una paz negociada y hasta colaboró en la represión, como refleja la dureza mostrada por los capellanes de prisiones o las recomendaciones a los párrocos para que no firmaran avales que evitaran fusilamientos en la retaguardia. La Iglesia católica se convirtió en uno de los pilares que mantuvieron la dictadura franquista $y$, frente a las actitudes adoptadas posteriormente por otras iglesias colaboradoras con dictaduras, como la argentina, nunca ha pedido perdón por su papel. El artículo concluye con una carta de Manuel de Irujo, vasco, católico y ministro en los gobiernos republicanos que se sucedieron durante la guerra, que muestra el dramatismo con el que los católicos que apoyaban las libertades democráticas vivieron la situación.

Dentro de la amplísima bibliografía sobre la Guerra Civil española, el tema relativo a las milicias voluntarias provenientes de las filas del carlismo -el llamado Requeté-, creadas o utilizadas para combatir a la Segunda República, y la ayuda que prestaron al éxito y la conversión del golpe del 18 de julio en una guerra civil, es una de las vertientes analíticas más novedosas, y un tema escasamente abordado en la historiografía. El artículo de Germán Ruiz Llano incluido en este monográfico analiza el porqué y el cómo de la organización del Requeté alavés y su origen y perfil socio-

\footnotetext{
37 Montero Moreno, Antonio, Historia de la persecución religiosa en España 1936-1939, Madrid: Biblioteca de los Autores Cristianos, 1961, calcula que 6.832 miembros del clero y de órdenes religiosas fueron asesinados o ejecutados. Sus datos no han sido modificados sustancialmente por investigaciones más recientes, aunque hay algunas matizaciones en Rodríguez Sánchez, Gregorio, El hábito y la crua: religiosas asesinadas en la guerra civil española, Madrid, Edibesa, 2006. En 1936 había en España algo más de 115.000 miembros del clero, lo que inclúa cerca de 45.000 monjas, 15.000 frailes, mientras que el resto eran curas. Se ha registrado que 2.365 monjes y 4.184 curas fueron asesinados, lo que constituía algo más del 30 por ciento de los monjes y del 18 por ciento de los curas del territorio republicano. Graham, Helen, La guerra y su sombra. Una visión de la tragedia española en el largo siglo XX europeo, Barcelona, Crítica, 2013, pág. 72.

38 También en el análisis de la experiencia italiana se demostró que la represión (que marginó a los oponentes y disidentes) no excluyó el consenso: Musiedlak, Didier, "El fascismo italiano: entre el consentimiento y el consenso", en Rollemberg, Denise y Viz Quadrat, Samantha (coords.), A construcao social dos regimes autoritários: Legitimidade, consenso e consentimento no século XX. Europa, Rio de Janeiro, Civiliçao Brasileira, 2010, págs.149-175.
} 
demográfico en un ámbito de tradicional economía rural y profunda identidad católica, características que están en el origen y la naturaleza de esta formación y de su movilización contra los valores laicos y progresistas de la política republicana de los años 30. El artículo muestra cómo la contraposición entre laicismo y catolicismo contribuyó a la formación de las identidades colectivas en la zona controlada por el bando sublevado. Como se señala en el texto, lo que uniría a todos los sectores socio-laborales y socio-profesionales en el Requeté, por encima de situaciones socioeconómicas, eran sus arraigadas convicciones religiosas.

La originalidad y mayor aportación de la investigación de Germán Ruiz Llano radica en que remonta su análisis a los años republicanos para advertir que en el espacio alavés, y en determinados municipios del mismo, la convivencia se había hecho ya insostenible: el laicismo, las relaciones con la Iglesia, la conflictividad socio-laboral y el miedo a un estallido revolucionario que rompiese con el tradicional modelo de vida y organización de la zona explican que el golpe del 18 de julio triunfase fácilmente en Álava, que fue la segunda provincia española en porcentaje de población que se alistó voluntariamente y la tercera en número total de voluntarios. A partir de esta constatación se muestran en el artículo las diferentes modalidades de movilización, que dependieron de las circunstancias de cada localidad: hubo lugares con auténticas levas masivas de voluntarios, donde prevaleció el entusiasmo; en algunos, la coacción o la obligación moral remiten a cierta dificultad en la movilización; mientras que en otros se realizó de manera espontánea e improvisada. En algunos casos, como señala el autor, fue la comunidad moral la que movilizó a los voluntarios con el fin de evitar males mayores y como medida defensiva de la comunidad. La familia extensa y las banderías (movilizados más por lealtades personales que políticas) también influyeron en el reclutamiento de estas milicias que tienen su génesis, según Ruíz Llano, en 'una sociedad rural basada en el patronazgo y la clientela, los fuertes lazos sociales y familiares'.

En este monográfico de Contenciosa, más allá de las batallas militares que dieron el triunfo al bando sublevado, hemos querido destacar el análisis de cómo se configuró durante la misma guerra el nuevo régimen franquista. $\mathrm{Y}$ es que la evolución de ambos bandos en conflicto no estuvo exenta de luchas internas, como nos muestran los artículos de Joan María Thomas y Julián Vadillo. En las dos últimas décadas han aparecido trabajos dedicados a la conflictividad que se dio en la llamada zona nacional, en la que Joan María Thomas es uno de los mayores expertos ${ }^{39}$. Estos estudios nos muestran una zona menos monolítica y armónica de lo que tradicionalmente se había considerado. Como analiza en su artículo el profesor Thomas, a través de las nuevas fuentes que han ido haciéndose accesibles con el paso de los años, el mismo ascenso del general Francisco Franco a la jefatura del Nuevo Estado no estuvo exento de tensiones. Mayores fueron los conflictos que se produjeron en Falange y en los tradicionalistas, tanto internamente como entre ellos. Así, la unificación en lo que se llamó Falange Española Tradicionalista y de las JONS, el partido único de la dictadura franquista, fue impuesta por Franco para dotarse, como se dice en este trabajo, de "su partido único de tipo fascista". Pero, precisamente por el limitado papel que le daba a éste, el franquismo no es homologable a un régimen propiamente fascista. Esto no quiere decir que en las primeras leyes promulgadas por el nuevo régimen ya durante la misma guerra, como se muestra en el texto, no estuviera la inspiración de los aliados nazis y fascistas. Provocaron también conflictos entre las diferentes sensibilidades políticas integradas en el nuevo partido. Estas tensiones nunca

39 Véanse, por ejemplo, Thomas, Joan María, El Gran Golpe. El «caso Hedilla» o cómo Franco se quedó con Falange, Barcelona, Debate, 2014, o José Antonio. Realidady mito, Barcelona, Debate, 2017. 
desaparecerían durante la dictadura franquista pero ya durante la Segunda Guerra Mundial llevaron al apartamiento de los viejos falangistas.

Por el contrario, como indica Julián Vadillo, pocas son las monografías que abordan la Guerra Civil que no se acerquen a los conflictos que surgieron en la retaguardia republicana casi desde el mismo inicio del enfrentamiento bélico. Estas tensiones, como bien se muestra en el artículo, venían de las diferentes posiciones mantenidas por las distintas fuerzas políticas que se sumaron a la defensa de la República. Estos conflictos tuvieron sus momentos álgidos en los sucesos de mayo de 1937 en Barcelona y en el golpe de Estado dirigido por el coronel Segismundo Casado en Madrid en marzo de 1939, que son detenidamente analizados en la contribución del doctor Vadillo. Más allá del papel del estalinismo o del anticomunismo, cuya influencia no se niega, hay que tener en cuenta también tensiones y desconfianzas que venían del periodo anterior a la guerra y la misma evolución del conflicto bélico y su complejidad internacional. Como ha dicho Helen Graham, el factor que modeló la evolución de la República entre 1936 y 1939 en todos sus aspectos "fue la guerra misma". ${ }^{40}$ Sin embargo, como nos muestra también el completo análisis bibliográfico que se realiza en el artículo, la abundancia de referencias y estudios sobre estos conflictos internos, no nos ha acercado, hasta hace poco tiempo, a la realidad de las situaciones que se vivieron, dado que durante varias décadas predominaron los relatos memoriales y partidistas a lo que se sumaba el mantenimiento en España de la dictadura franquista con su propia "versión" de estos procesos y la cerrazón de los archivos.

En la línea de intentar acercar a un público argentino algunas de las nuevas temáticas analizadas en los últimos años sobre el conflicto civil español, en lugar del conocido tema de las brigadas internacionales nos planteamos tratar otras formas de solidaridad internacional, ya que la guerra civil española y su impacto internacional galvanizaron los movimientos pacifistas y antifascistas. Las diferentes formas del antifascismo favorecieron también una solidaridad civil más allá de la militancia política en amplios sectores de población de diferentes países ${ }^{41}$. Así, la profesora Laura Branciforte analiza en este monográfico al Socorro Rojo Internacional (SRI) comunista y, en concreto, su sección española, una organización cuyo desarrollo, pero también su estudio, estuvo y ha estado condicionado por su vinculación a la Internacional Comunista. Partiendo de un necesario análisis de los orígenes del SRI en España y de su evolución en sus primeros años, la autora nos da otra prueba de que entre los principales protagonistas de los movimientos pacifistas y antifascistas estuvieron actores sociales que habían comenzado a actuar de forma independiente principalmente con el siglo $\mathrm{XX}$, como las mujeres y los jóvenes. ${ }^{42}$

La fecha detonante de la participación de las mujeres en la movilización antifascista en España fue octubre de 1934, pero dicha movilización no alcanzó su pleno desarrollo hasta la guerra civil, cuando el SRI se convirtió en un instrumento fundamental de la política asistencial en la retaguardia republicana, tanto en la ayuda a los niños y refugiados como en el cuidado de los heridos. Al igual que se ha planteado en cuanto al crecimiento del PCE durante la guerra, también en el SRI participaron personas que no eran estrictamente comunistas. Con la evolución de la situación europea en los años treinta, los antifascismos, aunque vinculados con la cultura política comunista, no

${ }^{40}$ Graham, Helen, The Spanish Republic..., op. cit., pág. 9.

${ }^{41}$ Pretus, Gabriel, La ayuda bumanitaria en la Guerra Civil española (1936-1939), Granada, Comares, 2015; Bocanegra Barbecho, Lidia, "Argentina en la Guerra de España", Historia del Presente, Eneida, Madrid, n’. 12 (2008/2), págs. 43-60.

${ }^{42}$ Souto Kustrín, Sandra, "El mundo que queremos crear': los congresos internacionales de la juventud y la crisis de entreguerras", Actas de las XI Jornadas Interescuelas/Departamentos de Historia, Tucumán, Universidad Nacional de Tucumán, 2007, 25 págs. 
llegaron a identificarse estrictamente con ésta, sino que adquirieron un carácter cada vez más amplio, diferenciado y democrático, incluyendo a fuerzas de izquierda, progresistas y liberales variadas. La historiografía europea de las últimas décadas ha renovado sus categorías interpretativas sobre el antifascismo, reevaluando su "dimensión cotidiana" y la importancia de la participación popular, y superando la idea de un antifascismo estático, monolítico y partidista. ${ }^{43}$

El artículo de Javier Puche Gil cubre también un espacio no muy transitado por la historiografía española sobre la guerra civil, como es el de la economía durante la misma guerra y el impacto económico de ésta. La reseña de esta nueva historia desmitificadora en cuanto a los aspectos económicos de la guerra ha sido abordada con muchísimo acierto por Barciela y López Ortiz recientemente $^{44}$. La principal virtud del texto de Puche es que presenta una apretada síntesis bibliográfica en torno a los elementos de consenso sobre los principales indicadores económicos y de salud. Se expone y evalúa no sólo el impacto económico de la contienda a nivel macro (Producto Interior Bruto (PIB), PIB per cápita, comercio exterior, sectores productivos...), sino también cómo evolucionó la economía en la zona republicana y en la rebelde (pues la contienda supuso una ruptura del mercado interior que se había ido configurando desde mediados del siglo XIX) y, como aspecto más novedoso, se reflejan las consecuencias que tuvo el conflicto ${ }^{45}$ desde el punto de vista del bienestar general (consumo, precios, salarios, coste de la vida, nutrición, mortalidad, enfermedades...). Javier Puche utiliza en su contribución técnicas de trabajo y de análisis de fuentes y datos estadísticos propios de la Historia Económica, recogidos en el artículo a través de numerosas tablas y gráficas. Destaca la evolución de la estatura media en España, como un nuevo indicador -las medidas antropométricas- que, desde la última década, está siendo abundantemente trabajado por los especialistas para medir la incidencia del bienestar y la calidad de vida en la salud y estado nutricional de las poblaciones. Los resultados muestran que la guerra truncó la tendencia al crecimiento económico del primer tercio del siglo XX, y que la mayor parte de la población (sobre todo los vencidos en la guerra), sufrieron una fuerte regresión de sus condiciones de vida y salud. Se estudia la evolución del Índice de Desarrollo Humano en España, concluyendo que los efectos socioeconómicos provocados por la Guerra Civil retrasaron en varios años la convergencia con Europa Occidental y los Estados Unidos, retrocediendo, en el caso de nuestro país, a niveles propios de los años veinte.

Y si hay un capítulo de la Guerra Civil española que desde el mismo momento del conflicto llamó la atención de los estudiosos, éste es el del exilio y los refugiados, una de las consecuencias más trágicas de la derrota militar de la II República, y a la que la historiografía especializada ha dedicado miles de páginas $^{46}$, pero que no agota su actualidad cuando conflictos de nuestro tiempo nos obligan a posicionarnos individual, ética y colectivamente, como es el caso de la llamada crisis de los refugiados en Europa. Sobre esta problemática, Beatriz Gracia Arce aborda una de las múltiples facetas del

${ }^{43}$ Collotti, Enzo (Coord.), Fascismo e antifascismo, Roma-Bari, Laterza, 2000.

${ }^{44}$ Barciela, Carlos y López Ortiz, $\mathrm{M}^{a}$ Inmaculada, "Una nación en crisis y dos economías enfrentadas. La historiografía económica de la Guerra Civil”, en Studia Histórica, Historia Contemporánea, Salamanca, 32, 2014, págs. 197-224.

${ }^{45}$ Como ya planteara Carlos Barciela, "la guerra no fue tan destructiva como la propaganda franquista se empeñó en sostener durante décadas'. Barciela, Carlos, "La Economía y la Guerra”, Pasado y Memoria, Alicante, no. 8, 2009, págs. 1334, pág. 26.

${ }^{46}$ Véanse, por ejemplo, Dreyfus-Armand, Geneviéve, El exilio de los republicanos españoles en Francia. De la guerra civil a la muerte de Franco, Barcelona, Crítica, 2000; Alted Vigil, Alicia, La voz de los vencidos. El exilio republicano de 1939, Madrid, Aguilar, 2005; Colomina Limonero, Inmaculada, Dos patrias, tres mil destinos. Vida y exilio de los niños de la guerra de España refugiados en la Unión Soviética, Madrid, Cinca, 2010; Dávila Valdés, Claudia, Refugiados españoles en Francia y México. Un estudio comparativo, El Colegio de México, México, 2012; Hoyos Puente, Jorge de, "La historiografía sobre refugiados y exiliados políticos en el siglo XX: el caso del exilio republicano español de 1939”, Ayer 106/2017 (2), Madrid, págs. 293-305. 
exilio cultural y político republicano a través del análisis de las travesías de los juristas Mariano RuizFunes en México y Luis Jiménez de Asúa en Argentina. Este exilio de juristas es mucho menos conocido, aunque es un sector socio-profesional que fue de los más represaliados por la dictadura franquista por el amplio apoyo que muchos de sus integrantes prestaron a la causa reformista de la Segunda República, como las dos figuras tratadas, que participaron en la elaboración de la ponencia constitucional, ejercieron de diputados e incluso de ministros durante el periodo de la República en paz y en los años de guerra.

Con la derrota de la República, cerca de medio millón de personas marcharon al exilio, fundamentalmente a Francia, pero tendieron a buscar, sobre todo después de la derrota de Francia ante la Alemania nazi, refugios seguros en países latinoamericanos que, como el México de Lázaro Cárdenas o Argentina permitieron, sobre todo al exilio más ilustrado y universitario, rehacer sus vidas y continuar sus obras de investigación y estudio, como sucedió en el caso de los dos personajes tratados en este artículo. La autora aborda las diferentes travesías del exilio experimentadas por ambos, analizando la naturaleza, características y ubicación en sus países de destino y su fundamental obra docente, académica y teórico-jurídica, siempre al calor de la reflexión de lo que significó la imposición de la dictadura de Franco en España y el estallido de la Segunda Guerra Mundial en Europa. Se muestran también las relaciones de amistad y ayuda entre los intelectuales exiliados, la resistencia a la dictadura que desarrollaron los dos penalistas en sus libros y acciones en la Universidad Nacional de México o en la Universidad de La Plata, y el reconocimiento que obtuvieron por su aportación docente, política y ética.

Más que las muertes en los enfrentamientos militares, lo que destaca de la guerra civil española es la represión en la retaguardia, donde se produjo más del 50\% de las víctimas de la guerra, aunque los datos podrían variar con investigaciones en curso o posteriores ${ }^{47}$. En este monográfico, en lugar de la represión producida en el bando republicano, se ha optado por incluir un artículo sobre la represión franquista y las políticas de memoria que se están desarrollando en la actualidad, no solo por las diferencias intrínsecas de la violencia producida en ambos bandos en conflicto, aunque asesinatos fueran todos y víctimas, en muchos casos indiscriminadas, también, si no por el diferente desarrollo de los estudios sobre ambos temas y la percepción pública de ellos.

No hay que olvidar tampoco que el periodo posterior a la caída del muro de Berlín, en 1989, no solo revivió el discurso de los derechos humanos, sino también "el de un opuesto discurso ultranacionalista, primero en Europa oriental, pero después también en Occidente”. Así, ha habido un reciclaje de los mitos de la guerra fría que ha permitido la reinvención de dirigentes autoritarios y/o fascistas como patriotas y nacionalistas sobre la base de su anticomunismo: los ultranacionalistas de Europa Central y Oriental idolatran a Franco como un anticomunista defensor de la civilización cristiana $^{48}$.

El mayor número de víctimas se produjo en la retaguardia de los sublevados, a pesar de que los territorios controlados por los republicanos concentraban una mayor densidad demográfica. La violencia franquista fue sistemática y dirigida desde arriba, mientras la republicana no fue premeditada ni dirigida, aunque tampoco puede reducirse a una acción descontrolada y espontánea. La violencia en la zona republicana se concentró principalmente en los inicios de la guerra -vinculada con la desarticulación de las estructuras estatales y políticas republicanas, cuando se produjo la

${ }^{47}$ Luengo, Félix y Aizpuru, Mikel, La Segunda República..., op. cit., pág. 220.

${ }^{48}$ Graham, Helen, “Writing Spain’s...”, op. cit., págs. 11 y 12. 
principal matanza de facciosos, la de Paracuellos del Jarama, en las afueras de Madrid, cuyas víctimas fueron recuperadas, recordadas y homenajeadas durante los casi cuarenta años de franquismo-, y en los momentos finales del conflicto bélico. En el ínterin, la República buscó reconstruir y preservar los controles democráticos y constitucionales del Estado. Fue el impacto del deterioro de la situación militar el que llevó a nuevos fenómenos de violencia indiscriminada según avanzaba el año 1938, especialmente entre las tropas en retirada tras la derrota en la batalla del Ebro ${ }^{49}$.

Sin embargo, el interés por conocer la historia de la represión franquista, que continuaría durante toda la dictadura, y, especialmente, durante los primeros años de la posguerra, y de sus represaliados, de aquellos que vivieron un duro exilio interior -los grandes olvidados tras el pacto que dio lugar a la transición política- no se desarrolló hasta la última década del siglo XX, influido también por trabas administrativas y archivos cerrados, y ha sido la historia local la que "más y mejor ha renovado" el conocimiento de estas temáticas ${ }^{50}$.

Todo esto destaca la importancia del trabajo presentado en este monográfico por los doctores en Historia Francisco Javier Giráldez Díaz y Miguel Ángel Melero Vargas, responsables de la Dirección General de Memoria Democrática de la Consejería de Cultura de la Junta de Andalucía, una de las comunidades autónomas españolas que más ha hecho, y desde hace más tiempo, por recuperar a las víctimas de la represión franquista, pero cuyas circunstancias y conclusiones se podrían extrapolar al conjunto del Estado español y a la problemática, social, política y, quizá fundamentalmente, ética, que plantea en la actualidad en España la especialmente dolorosa persistencia de fosas comunes de víctimas de la guerra civil y el franquismo. Los autores de este texto nos muestran el carácter de esta represión extrajudicial, la formas en que el recuerdo -pero también los intentos de olvido y el silencio- se desarrollaron a lo largo de los años oscuros de la dictadura (con la interesante idea de prememoria), las primeras acciones, en algunos casos aisladas, de los ayuntamientos elegidos democráticamente por primera vez en más de 40 años en 1977, y el paso, ya en el siglo XXI, de las iniciativas familiares a las políticas públicas de memoria, todavía hoy acechadas por muchas resistencias políticas, incluidas las del actual gobierno de España, que consideran que hablar de los crímenes del franquismo es "reabrir heridas", cuando verdaderamente las heridas solo podrán cerrarse cuando todas las víctimas -lucharan con quien lucharan- tengan un entierro digno y decente.

Solo nos queda añadir nuestro agradecimiento al Comité de Redacción de la revista Contenciosa, especialmente a su director, Luciano Alonso, y a su secretaria de redacción, Cecilia Tonon, por su interés en la Guerra Civil española y su confianza al proponernos la elaboración de este monográfico, y en especial a los investigadores que colaboran en él, que aceptaron con entusiasmo participar y que han realizado trabajos novedosos, de gran interés y esmerada elaboración. A todos, muchísimas gracias.

Este monográfico está dedicado a la memoria de Julio Aróstegui Sánchez (1939-2013), maestro de muchos de nosotros, amigo de todos, un gran experto en República, Guerra Civil, violencia y memoria y, en cierto modo, alma de la revista Contenciosa, en la que, como nos dijo uno de los

${ }^{49}$ Ledesma, José Luis, Los días de llamas de la revolución: violencia y politica en la retaguardia republicana de Zaragoza durante la guerra civil, Zaragoza, Institución Fernando El Católico, 2003; Preston, Paul, El holocausto español. Odio y exterminio en la guerra civily después, Barcelona, Debate (Random House, Mondadori), 2011; Ruiz, Julius, Paracuellos: una verdad incómoda, Madrid, Espasa, 2015; Cervera, Javier, Contra el enemigo de la República desde la ley: detener, juzgar y encarcelar en guerra, Madrid, Biblioteca Nueva, 2015.

${ }^{50}$ Casanova, Julián, "Una dictadura de 40 años", en Casanova, Julián, Espinosa, Francisco, Mir, Conxita, y Moreno Gómez, Francisco, Morir, matar, sobrevivir. La violencia en la dictadura de Franco, Barcelona, Crítica, 2002, 2a. ed., págs. 3-50, pág. 43. Un estudio pionero fue el de Juliá, Santos (Coord.), Victimas de la guerra civil, Madrid, Temas de Hoy, 1999. 
integrantes de su equipo de dirección, “también están sus manos mágicas”. Siguiendo la letra de un poema que a él le gustaba mucho, temprano levantó la muerte el vuelo (Elegía a Ramón Sijé, Miguel Hernández, Orihuela, 1910-cárcel de Alicante, 1942, víctima de la represión franquista).

Madrid y Murcia, julio de 2017 